ARTIGOS

\title{
RESIDÊNCIA PEDAGÓGICA NAS IES: PROGRAMA DE APERFEIÇOAMENTO DO ESTÁGIO CURRICULAR OBRIGATÓRIO?
}

\author{
Fernanda SilvaVELOSO \\ Universidade Federal do Paraná - UFPR \\ Curitiba, PR-Brasil \\ fernandaveloso@ufpr.br \\ 0000-0002-5263-6479 \\ Altair PIVOVAR \\ Universidade Federal do Paraná-UFPR \\ Curitiba, PR-Brasil \\ pivovarit@ufpr.br \\ 0000-0003-1156-9342
}

RESUMO: Este artigo tem a intenção de expandir a discussão sobre o programa Residência Pedagógica (PRP) inserindo no debate um aspecto de fundamental importância para a compreensão das dificuldades de implementação de uma efetiva política de estágio, universal e isonômica, e não apenas ações isoladas. Com base numa breve análise do teor dos Editais CAPES 06/2018 e 01/2020, depreende-se, do pano de fundo da proposta lançada, a esquiva do enfrentamento direto do estágio curricular obrigatório, desconsiderando todo um percurso histórico de construção conceitual.A fim de refletir sobre tal questão, foi feita, neste texto, uma análise teórico-qualitativa suportada por dados documentais e também bibliográficos. Em face das condições incipientes do programa, os autores consideram desaconselhável se garantir equivalência do estágio obrigatório a discentes que participem do PRP, reconhecendo que se impõe a reconfiguração do estágio para formação de professores do ponto de vista operacional, para que, respeitadas as especificidades, possa efetivamente ser posto em prática.

PALAVRAS-CHAVE: Residência pedagógica. Estágio supervisionado. Formação de professores.

\section{PEDAGOGICAL RESIDENCE IN UNIVERSITIES: PROGRAM FOR IMPROVING THE MANDATORY TEACHING PRACTICUM?}

\footnotetext{
ABSTRACT: This article intends to expand the discussion on Pedagogical Residence Program (PRP) by inserting into the debate an aspect of fundamental importance for understanding the difficulties of implementing an effective, universal and isonomic teaching practice policy, and not only isolated actions. Based on a brief analysis of the content of the Public Notices CAPES 06/2018 and 01/2020, and on the background of the launched proposal, the avoidance of direct confrontation of the mandatory curricular supervised 
teaching practicum, disregarding the entire historical path of conceptual construction is apparent. Taking into consideration the incipient conditions of the program, the authors consider it inadvisable to guarantee equivalence of the mandatory practicum to students who participate in the PRP, recognizing that, if so, it will be necessary to reconfigure the teaching supervised practice to educate teachers from an operational point of view, so that, respecting the specificities, it can be effectively put into practice.

KEYWORDS: Pedagogical residence. Supervised teaching practicum. Teacher education.

\section{RESIDENCIA PEDAGÓGICA EN UNIVERSIDADES: ¿PROGRAMA DE MEJORA DE LAS PRÁCTICAS CURRICULARES OBLIGATORIAS?}

RESUMEN: Este artículo pretende ampliar la discusión sobre el programa Residencia Pedagógica (PRP) insertando un aspecto de fundamental importancia para entender las dificultades de implementar una política de pasantías efectiva, universal e isonómica, y no solo acciones aisladas. A partir de un breve análisis del contenido de los Avisos Públicos CAPES 06/2018 y 01/2020, se desprende del trasfondo de la propuesta lanzada, la evitación del enfrentamiento directo de la pasantía curricular obligatoria, desconociendo todo el camino histórico de construcción conceptual. Ante las incipientes condiciones del programa, los autores consideran desaconsejable garantizar la equivalencia de la pasantía obligatoria a los estudiantes que participan en el PRP, reconociendo que es necesario reconfigurar la pasantía para formar docentes desde un punto de vista operativo, para que, respetando las especificidades, se pueda realmente se poner en práctica.

PALABRAS-CLAVE: Residencia pedagógica. Pasantía supervisada. Formación de profesores. 


\section{INTRODUÇÃO}

Desde sua adoção em formas mais incipientes, o estágio curricular supervisionado na formação de professores, pelas suas peculiaridades, tem sido atividade de ensino de difícil equacionamento, de modo que o lançamento de políticas e programas governamentais que promovam a superação dos obstáculos ao pleno atingimento de seus objetivos deveria ser iniciativa recebida com entusiasmo.

Contudo, sempre que há o lançamento pelo governo de propostas envolvendo a figura do estágio para a formação de professores, instaura-se a polêmica. Tem sido assim com as normativas sobre o estágio nas sucessivas diretrizes curriculares - vide as críticas à concepção de estágio na recente Resolução 02/2019 -, foi assim com o PIBID(Programa Institucional de Bolsa de Iniciação à Docência) na sua primeira versão (reação amenizada quanto à segunda) e foi assim com o programa Residência Pedagógica (PRP).

Sendo a figura do estágio incontestavelmente reconhecida como fundamental para a formação docente, é de se perguntar o porquê da desconfiança e relutância em aderir às propostas.

O estágio curricular das licenciaturas é realizado por meio de disciplinas que são ofertadas desde o início do curso, conforme estabelecido no inciso $6^{\circ}$ do artigo 13 da Resolução CNE/CP 02/2015 (BRASIL, 2015),com atividades que vão desde a compreensão da estrutura escolar até a regência de aulas. A carga horária de 400 horas, estipulada tanto pela resolução CNE/CP 02/2015 quanto pela CNE/CP 02/2019, não é recente. Foi com a publicação do Parecer n²8/2001 (Brasil, 2002) que se chegou a esse número.

Antes disso, a Lei de Diretrizes e Bases (LDB) - Lei 9.394/1996 - exigia carga horária mínima de trezentas horas, mas já pressupunha, em seu artigo 61, que "a formação de profissionais da educação [...] terá como fundamentos: [...]; II - a associação entre teorias e práticas, mediante estágios supervisionados e capacitação em serviço" (BRASIL, 1996, grifos nossos). A partir dessa lei é que foram propostasas Diretrizes Curriculares Nacionais (DCNs) de formação de professores de 2001.

No parecer CNE/CP 28/2001, o estágio curricular supervisionado se caracteriza como "atividade intrinsecamente articulada com a prática e com as atividades de trabalho acadêmico". De acordo com o referido parecer:

[...] 2000 horas de trabalho para execução de atividades científico-acadêmicas somadas às 400 horas da prática como componente curricular e às $\mathbf{4 0 0}$ horas de estágio curricular supervisionado são o campo da duração formativa em cujo terreno se plantará a organização do projeto pedagógico planejado para um total mínimo de 2800 horas. (BRASIL, 2002, p. 10, grifos nossos)

Com esse parecer, segundo Rodrigues (2013, p. 1012), "acabam-se as divergências em relação à carga horária dos cursos de formação de professores, bem como à importância do estágio supervisionado para o futuro docente".

Das 20 metas do Plano Nacional de Educação (PNE 2014-2024), algumas são voltadas à formação de profissionais do magistério, como a meta 15, que incide diretamente na formação inicial dos professores, assegurando "que todos os professores e as professoras da educação básica possuam formação específica de nível superior, obtida em curso de licenciatura na área de conhecimento em que atuam".

A aprovação do PNE resulta na Lei 13.005/2014, que dá início a uma nova etapa para as políticas educacionais brasileiras. Juntos, o PNE e as novas DCNs para a Formação Inicial e Continuada dos Profissionais do 
Magistério da Educação Básica, definidas pela Resolução CNE/CP 2/2015, buscam dar mais organicidade para a educação nacional no decênio em questão.

Com relação especificamente ao estágio supervisionado, as DCNs de 2015 avançam ao afirmar que o estágio tem um caráter teórico-prático. As diretrizes se destacam principalmente por encarar teoria e prática como "unidade" (VÁSQUEZ, 1968), não mais entendendo a teoria como presente exclusivamente na universidade, e a prática, na escola. Desse modo, o projeto de formação inicial de professores só pode ser elaborado e desenvolvido a partir de uma articulação entre a Instituição de Ensino Superior (IES) e a unidade de ensino da educação básica.

No que diz respeito à conceituação de estágio, muito vem sendo discutido em contexto nacional. Dentre os autores que já trataram do assunto, destacamos Pimenta e Lima. Para essas autoras, compete ao estágio "possibilitar que os futuros professores compreendam a complexidade das práticas institucionais e das ações aí praticadas por seus profissionais como alternativa de preparo para sua inserção profissional" (PIMENTA e LIMA, 2010, p. 43). Dessa forma, o estágio deve preparar para um trabalho coletivo, "uma vez que o ensino não é um assunto individual do professor, pois a tarefa escolar é resultado das ações coletivas dos professores e das práticas institucionais, situadas em contextos sociais, históricos e culturais" (PIMENTA e LIMA, 2010, p. 56).

As autoras, ainda, defendem a concepção de estágio como campo do conhecimento e como campo de pesquisa. Nesse caso, a prática docente realiza-se como "uma atitude investigativa, que envolve a reflexão e a intervenção na vida da escola, dos professores, dos alunos e da sociedade" (PIMENTA e LIMA, 2010, p. 34).

Foi com a publicação das recentes DCNs -Resolução CNE/CP 02/2019 - que nos deparamos com uma nova concepção de estágio nos documentos normativos emitidos pelo Ministério da Educação (MEC). A formação inicial docente apresenta agora uma ênfase excessiva na dimensão prática, chamada de racionalidade prática, não sendo mais pensada como práxis pedagógica, o que simplifica e reduz o seu entendimento.

As críticas realizadas até o momento apontam para uma total desconsideração dos debates educacionais e para a retomada de pressupostos já superados e duramente criticados na formação docente, especialmente quanto à segmentação da teoria e da prática e ao praticismo, acarretando a superficialidade da formação.

Se, nas DCNs de 2015, o conteúdo é visto pelos profissionais da educação como "uma importante e bem elaborada síntese das lutas históricas da área em torno ao tema" (BAZZO e SCHEIBE, 2019, p. 671), nas DCNs de 2019 temos um conteúdo que "evidencia a desvalorização da produção e do pensamento educacional brasileiro ao retornarem para a concepção da pedagogia das competências, alinhadas nas competências previstas na BNCC" (CINTRA e COSTA, 2019, p. 14).

Circunscrito o tema mais amplo em que se inserem as discussões aqui empreendidas, será realizado, ao longo do texto, uma análise teórico-qualitativa suportada por dados documentais, e também bibliográficos, que nos possibilitem abordar a problemática específica e responder à pergunta feita no título deste texto: o PRP é, de fato, um programa de aperfeiçoamento do estágio curricular obrigatório como proposto pela CAPES?

\section{O PROGRAMA RESIDÊNCIA PEDAGÓGICA (PRP)}

Como apontado por Silva e Cruz (2018), "a questão da residência na área da Educação não é uma discussão nova no Brasil e tem surgido também sob diferentes nomenclaturas." O termo residência é muito conhecido pelos brasileiros, principalmente quando o assunto é a formação dos médicos, a ponto de a única expressão encontrada no dicionário Michaellis com o termo residência ser justamente "residência médica". 
Com base nesse programa de formação voltado aos alunos egressos do curso de Medicina, em 2007 surge, no Senado, a ideia de estendê-lo à área da Educação. Muitos foram os projetos de lei propostos, mas que não chegaram a ser implantados. Não obstante, algumas poucas experiências exitosas de residência no campo da formação de professores foram realizadas Brasil afora.

O PRP CAPES foi lançado em 2018, por meio do Edital Capes 06/2018. O objetivo desse edital era selecionar, no âmbito do PRP, IES para implementação de projetos inovadores que, conduzidos em parceria com as redes públicas de educação básica, estimulassem a articulação entre teoria e prática nos cursos de licenciatura. Atualmente, a estrutura e funcionamento do PRP são regulamentados pela Portaria CAPES 259, de 17 de dezembro de 2019.

Assim como o PIBID, esse programa também "transita nos mesmos espaços institucionais em que se aplica a atuação dos estagiários" (PIMENTA e LIMA, 2019), mas, diferentemente daquele, que nunca se definiu como estágio, o PRP, desde seu primeiro edital, já tinha como um de seus objetivos constituir-se como base para a reformulação do estágio supervisionado nos cursos de licenciatura.

Os projetos institucionais de PRP têm vigência de 18 meses, com carga horária total de 414 horas de atividades, organizadas em 3 módulos de seis meses com carga horária de 138 horas cada módulo. Tais módulos devem, necessariamente, contemplar as seguintes atividades:

a) 86 horas de preparação da equipe, estudo sobre os conteúdos da área e sobre metodologias de ensino, familiarização com a atividade docente por meio da ambientação na escola e da observação semiestruturada em sala de aula, elaboração de relatório do residente juntamente com o preceptor e o docente orientador, avaliação da experiência, entre outras atividades;

b) 12 horas de elaboração de planos de aula; e

c) 40 horas de regência com acompanhamento do preceptor. (BRASIL, 2020)

Os participantes do PRP deverão se comprometer com, no mínimo, 23 horas de dedicação mensal. O professor preceptor acompanhará até no máximo 10 residentes, enquanto o professor orientador terá a tarefa de orientar até, no máximo, 30 graduandos. Para participar do subprojeto do PRP, o licenciando deverá necessariamente ter cursado o mínimo de $50 \%$ do curso ou estar cursando a partir do $5^{\circ}$ período e ser aprovado em processo seletivo realizado pela IES.

Ainda são poucas as pesquisas sobre o tema do PRP CAPES, dado que o programa só foi implementado em algumas universidades a partir de 2018. Alguns dos artigos que encontramos consideram como ponto positivo a iniciativa da CAPES de permitir a construção de uma prática pedagógica em que a escola tenha um papel significativo e que de algum modo privilegie o protagonismo da instituição escolar, bem como por trazer contribuições ao processo formativo inicial dos estudantes.

Outros, por sua vez, tecem duras críticas ao PRP, principalmente por: 1) ser refém da Base Nacional Comum Curricular (BNCC); 2) fragmentar "a unidade teoria e prática e colocar a ênfase na prática como concepção utilitarista da formação de professores" (SILVA e CRUZ, 2018, p. 238; ANPED, 2018); 3) atrelar o estágio curricular supervisionado a uma perspectiva de aperfeiçoamento por meio da PRP (ARAÚJO, 2019); e 4) ferir a autonomia universitária quando apresenta a indução da reformulação do estágio supervisionado nos cursos de Licenciatura (UFG, 2018; UFPR, 2018).

Apresentados os polos da oposição, estágio e residência pedagógica, o próximo passo é identificar o lugar que esta ocupa em relação àquele nos editais CAPES. 


\section{CESSE TUDO O QUE A MUSA ANTIGA CANTA...}

A polêmica se instaura a partir do instante em que o documento separa as figuras do estágio curricular supervisionado e do PRP e passa a contrapor a uma figura real, historicamente constituída, uma figura ainda por compreender, mas que vem já revestida de precedência sobre a anterior. A reação advém tanto do que é dito quanto do que é silenciado nos editais CAPES 06/2018 e 01/2020.

A linguagem de ambos os editais deixa transparecer a dificuldade do governo de enfrentar a disciplina real, que foi tomando suas atuais feições ao longo dos anos e hoje ocupa espaço considerável da carga horária dos cursos de licenciatura. O desconforto gerado por essa dificuldade manifesta-se na intenção de pôr essa figura pedagógica de lado (mudando-lhe até mesmo a designação) para, destituída de vigor, fazê-la morrer à míngua até desaparecer. Essa intenção fica patente no item 2.1/ll do Edital 06/2018:

\subsection{O Programa de Residência Pedagógica visa: \\ II. Induzir a reformulação do estágio supervisionado nos cursos de licenciatura, tendo por base a experiência da residência pedagógica;}

Presentes neste item três importantes aspectos: um objetivo, um diagnóstico e um postulado. O objetivo (induzir a reformulação do estágio supervisionado) parte de um diagnóstico implícito (o de que o estágio não estaria sendo satisfatório); o postulado é o de que o PRP resolveria o problema histórico do estágio curricular, acabando com o incômodo. A morte do estágio curricular pela míngua vinha decretada no item 4.3/ III - dos requisitos para a participação das IES: "Comprometer-se em reconhecer a residência pedagógica para efeito de cumprimento do estágio curricular supervisionado".

A proposta assim delineada, se, por um lado, trouxe preocupação a algumas IES, atendeu a angústia de muitas outras, por acenar com condições diferenciadas de tratamento das atividades de estágio, desobrigando-as de se preocupar com os reais problemas enfrentados hoje por essa atividade (seria o caso apenas de esperar ele ser totalmente substituído pelo novo modelo), tendo de lidar nesse intervalo de tempo com menor número daqueles que ainda precisariam do estágio nos moldes atuais, por conta da equivalência das atividades de RP com as de estágio supervisionado.

Esse dispositivo, nos limites propostos, aposta no esmaecimento processual do estágio curricular obrigatório nos moldes atuais, que continuaria por algum tempo a persistir no currículo para dar conta daqueles que não seriam contemplados no programa enquanto ele não fosse universalizado - pelo menos éa inferência que pode ser feita levando em conta que o documento previa a "reformulação do estágio supervisionado nos cursos de licenciatura, tendo por base a experiência da residência pedagógica".

Essas duas determinações receberam nova redação na versão seguinte do programa, consubstanciada no Edital 01/2020:

3.1.1. O Programa de Residência Pedagógica é uma das ações que integram a Política Nacional de Formação de Professores e tem por objetivo induzir o aperfeiçoamento da formação prática nos cursos de licenciatura, promovendo a imersão do licenciando na escola de educação básica, a partir da segunda metade de seu curso.

$[\ldots]$

6.4. A IES deverá se comprometer em reconhecer a carga horária das atividades realizadas pelo residente no programa para aproveitamento de créditos no curso. (grifos nossos) 
Deveríamos concluir disso que tais modificações passaram a dar melhor tratamento às relações entre PRP e estágio? Definitivamente, não; impõe-se reconhecer justamente o contrário. Em primeiro lugar, porque apenas amenizou o teor das afirmativas do edital anterior, sem, contudo, alterá-lo (em que outra atividade a carga horária da residência poderia ser convertida em créditos no curso senão no estágio, por similaridade?). Isso na verdade piorou o diálogo, no sentido de que o estágio foi sumariamente silenciado no Edital 01/2020.

Se o Edital 06/2018 previa o desaparecimento gradual - por inércia - do estágio supervisionado, o Edital 01/2020 já o tem como extinto: nesse documento, o termo "estágio" aparece em três únicas ocorrências, todas designando uma figura já do passado:

8.1. São requisitos mínimos para o recebimento de bolsa de Coordenador institucional: [...]

VI - Possuir experiência na formação de professores, comprovada por pelo menos dois dos seguintes critérios:

a) Docência de disciplina de estágio curricular em curso de licenciatura; [...]

8.2. São requisitos mínimos para o recebimento de bolsa de docente orientador: [...]

VII - Possuir experiência na formação de professores, comprovada por pelo menos dois dos seguintes critérios:

a) Docência de disciplina de estágio curricular em curso de licenciatura; [...]

8.4. São requisitos mínimos para o recebimento de bolsa de residente: [...]

8.4.1. O estudante de licenciatura que possuir vínculo empregatício ou estiver realizando estágio remunerado, poderá ser bolsista do programa de residência pedagógica, desde que não possua relação de trabalho com a IES participante ou com a escola onde desenvolverá as atividades do subprojeto. (grifos nossos)

Ou seja, só faz referência a "estágio" nos momentos em que está referindo uma situação de um passado - portanto, coisa já existente - em que o termo foi utilizado. Quando se trata do programa atual, evita-se remeter ao "estágio" ancestral. Não deve ser sem intenção que o documento nega até a nomenclatura da atividade - só não nega totalmente porque "estágio" (do latim medieval stagium) significava "residência, morada".

Consciente ou inconscientemente, há de ter sido esse o estopim da polêmica nesse caso, o que redundou em diferentes reações de aceitação no primeiro momento, sendo o principal motivo do adiamento da implementação do PRP em várias IES, entre elas a Universidade Federal do Paraná (UFPR), nosso local de fala. Mesmo entre as que aderiram ao programa, houve diferentes modos de implementação, cujo aspecto crucial de diferenciação era a equivalência entre as atividades desenvolvidas no PRP e as do estágio curricular supervisionado, denotando falta de unidade - ressalte-se que já se comentou aqui que uma das importantes contribuições atribuídas ao Parecer 28/2001 foi ter acabado com divergências entre os modos de tratar as cargas horárias nas licenciaturas.

Como já mencionado, muitas foram as IES que a partir de 2018 começaram a considerar parte da carga horária, até mesmo a carga horária total, como aproveitamento de estudos para fins de cômputo de carga horária dos estágios curriculares supervisionados dos cursos de licenciatura.

O que pudemos observar consultando os documentos emitidos por IES é que todas elas, mesmo com a possibilidade de não mais precisar considerar as horas de atividades do PRP como equivalentes às horas de estágio obrigatório, mantiveram as suas instruções normativas e/ou resoluções. A tabela a seguir apresenta alguns desses documentos e a maneira como cada instituição escolheu realizar o referido aproveitamento. 


\begin{tabular}{|c|c|c|}
\hline IES & DOCUMENTO & PORCENTAGEM DE CONVERSÃO \\
\hline UFMA & Nota Técnica 02/2018 PROEN & $100 \%$ \\
\hline UEM & Portaria 13/2019 PEN & $\begin{array}{c}\text { o critério de conversão baseia-se } \\
\text { no previsto nas exigências de cada } \\
\text { curso (cada curso criou a sua própria } \\
\text { resolução) }\end{array}$ \\
\hline UFAL & Instrução Normativa 01/2018 PROGRAD & $100 \%$ \\
\hline UFERSA & Instrução Normativa 01/2019 PROGRAD & $100 \%$ \\
\hline UFES & Instrução Normativa 04/2019 DRCA/ & $20 \%$ \\
\hline UFT & Nota Técnica 02, de 24/04/2019 & parcial ou integral, a partir da \\
\hline UEMA & Reciação dos colegiados dos cursos \\
\hline UEG & Resolução Csa 1.057, de 11/04/2018 & máximo de 90 horas (22\%) \\
\hline UFSM & Resolução 02/2019 PROGRAD & $100 \%$ \\
\hline UNIPAMPA & Instrução Normativa 01/2018 PROGRAD & $100 \%$ \\
\hline IFRN & Nota Técnica 2/2018 PROEN/RE/IFRN & $100 \%$ \\
\hline
\end{tabular}

Chegamos, assim, ao escopo deste artigo, qual seja, levantar pontos de discussão no embate gerado pela seguinte indagação: por serem de naturezas parecidas e ocuparem os mesmos espaços pedagógicos, seria lícito garantir a equivalência do estágio obrigatório a discentes que participem do PRP?

\section{EQUIVALÊNCIA ENTRE ESTÁGIO OBRIGATÓRIO E PRP}

O estágio supervisionado, segundo as DCNs 02/15, como já explicitado, é "componente obrigatório da organização curricular das licenciaturas, sendo uma atividade específica intrinsecamente articulada com a prática e com as demais atividades de trabalho acadêmico." Sendo assim, para muitos soou de pronto inaceitável que as horas cumpridas pelos discentes residentes pudessem substituir as horas de estágio obrigatório, como proposto pelo Edital CAPES 06/2018.

Diante dessa constatação, houve inúmeras manifestações contrárias ao PRP emitidas por colegiados, fóruns e entidades ligadas ao ensino superior. Entre elas, citamos o posicionamento de ANPED, ANFOPE, FORUMDIR e ANPAE. Em documento único, publicado em 06 de março de 2018, tais entidades rechaçaram a proposta de "reformulação do atual modelo de Estágios Supervisionados dos cursos de Licenciatura das IES públicas e privadas sem fins lucrativos" (2018). 
Em seguida, muitas IES começaram a endossar esse documento. Na UFPR, depois de debates promovidos pelo Setor de Educação, optou-se por não aderir ao PRP. Entre as justificativas elaboradas pelo CEALI' , em avaliação do Edital CAPES 06/2018 dirigida à comunidade universitária, estava a de que o PRP feria a "autonomia de organização pedagógica dos cursos de licenciatura, ignorando suas especificidades".

Nesse sentido, o Edital CAPES 06/2018 não só estaria induzindo à reformulação do estágio supervisionado nos cursos de Licenciatura, como afrontaria normas internas das IES relativas à política de estágio, entre elas o número máximo de alunos (15) por turma de estágio, como ocorre na UFG (2018) e na UFPR².

Segundo um documento produzido pela ANPED (2018), o que estava sendo proposto pelo Edital CAPES 06/2018 era um retorno ao modelo de estágio num formato conservador e tradicional, isto é, a "redução à atividade prática instrumental" (PIMENTA e LIMA, 2010): observação, participação e regência.

Um estudo realizado por Jardilino em 2014 já destacava a problemática existente nas IES acerca da equivalência entre PIBID e estágio obrigatório. O autor aponta que uma das demandas que surgiram em seu estudo foi justamente a reivindicação de estudantes de alguns cursos da universidade em que atua como docente para que a participação no PIBID tivesse algum tipo de validade como estágio supervisionado.

Para o autor, cada ação estabelece as suas próprias especificidades. Enquanto o estágio supervisionado vincula-se a um componente curricular obrigatório, o PIBID é um programa da CAPES/MEC que atende a um grupo de alunos das licenciaturas previamente selecionados pela universidade. Outra diferença importante entre os dois é a concessão de bolsas para todos os envolvidos no programa CAPES, enquanto no estágio obrigatório não existe nenhum tipo de verba destinada a alunos e professores supervisores.

Em estudo publicado recentemente, Pimenta e Lima (2019) também realizaram uma excelente análise dos embates criados pela política que opõe o estágio obrigatório ao PIBID. Entre as constatações das autoras, está a de que o PIBID e o estágio obrigatório:

mesmo que aparentemente sejam propostas semelhantes, pertencem a campos de poder, estrutura, funcionamento e condições objetivas diferentes. Enquanto o PIBID se movimenta pelo incentivo das bolsas, direcionadas a coordenadores, alunos e professores da escola recebedora, o estágio é mobilizado pela obrigatoriedade da legislação curricular. [...] o estágio supervisionado mostra ser mais abrangente que o PIBID, uma vez que aponta para a compreensão das contradições, das possibilidades e dos limites de uma escola pública dialeticamente situada.

A partir da discussão proposta pelas autoras, podemos concluir que não é possível fornecer equivalência entre PIBID e estágio supervisionado. Afinal, o segundo vai muito além das propostas implementadas em uma ou outra "escola recebedora", como já apontava Jardilino em 2014. Para esse autor, "o PIBID pode ser considerado como mais uma das formas de manutenção e de efetivação do vínculo entre aluno em formação inicial e professores em atuação" (2014, p. 362).

1 O Centro de Articulação das Licenciaturas (CEALI) é uma unidade do Setor de Educação da UFPR, consultiva, com a finalidade de discutir e propor políticas de formação de professores no âmbito do Setor.

2 Em 2020, com o lançamento do Edital 01/2020, a comunidade acadêmica da UFPRacolheu o referido programa e iniciou a sua participação com nove núcleos de variados cursos de licenciatura. 
Depois de tantas críticas e manifestações contrárias ao Edital nº6/2018, o único aspecto repensado pela CAPES em novo editalfoi a possibilidade - não admitida explicitamente - de manutenção, pela IES, da trajetória formativado estágio obrigatório, ficando o PRP como formação complementar. Importante frisar que admite a existência, mas não acena com a menor intenção de tratar das condições dessa "existência". Isso acaba gerando uma série de questionamentos que precisam ser esclarecidos antes de se atribuir ao PRP o mesmo estatuto do estágio obrigatório.

É claro que com a aprovação e publicação da Resolução CNE/CP 02/2019, o argumento de que a concepção de estágio proposta no PRP e nas diretrizes eram contraditórias caiu por terra. Afinal, num curto espaço de tempo, houve a substituição da Resolução CNE/CP 02/2015, deixando a formação docente de ser vista como práxis pedagógica e passando a ser voltada para os aspectos de instrumentalização técnica do exercício profissional.

Nessa nova resolução, temos uma concepção de professor que contraria aquela presente na Resolução CNE/ CP 02/2015, mas que, ao mesmo tempo, coaduna com a concepção de formação imbricada nos editais do PRP. A noção de professor pesquisador e do "estágio marcado pela pesquisa" (PIMENTA e LIMA, 2010), em destaque na Resolução CNE/CP 02/2015 - e em certa medida presente ainda no Edital CAPES 06/2018 -, dá lugar agora à segmentação da teoria e da prática e ao praticismo, acarretando a superficialidade da formação dos professores.

Além disso, temos agora uma concepção de currículo comum tanto na Resolução CNE/CP 02/2019 quanto nos editais do PRP, dado que a BNCC tornou-se o documento norteador de ambos.

\section{AS IMPRESCINDÍVEIS PONDERAÇÕES}

Percorrido esse trajeto, importante enfatizar que não se pretende aqui discutir o PRP em si - seus pontos negativos ou positivos -, até porque as poucas pesquisas sobre o tema, em sua maioria, dado o pouco tempo de existência das iniciativas, apresentam mais as impressões dos agentes (preceptores, tutores e residentes) do que dados objetivos. O que se quer pôr em foco é o silenciamento quanto ao que fazer com o estágio, aspecto que consideramos mais problemático.

Tal como foi apresentada, a proposta soa como tentativa de resolver um problema propondo que se desvie o olhar para outra direção, tirando-o do campo de visão. Isso porque, dê-se equivalência do PRP ao estágio obrigatório ou não, este continuaria existindo, pelo menos até a universalização da residência.

Por essa razão, antes de se reconhecer no PRP as mesmas prerrogativas curriculares do estágio, alguns aspectos carecem de esclarecimentos, sendo os principais:

1) A RP vai ser curricularizada e universalizada, isto é, alcançar automática e indistintamente todos os licenciados?

2) Isso ocorrendo, as bolsas continuarão a ser concedidas e contemplarão todos os agentes?

3) Há um tempo previsto para a existência do PRP como programa? Se, no caso de uma ação suplementar e opcional, cuja carga horária resultante seria acrescida à formação, essa pergunta não teria relevância, no caso da RP, em que ela poderá fazer as vezes da carga horária obrigatória, esse prazo é de suma importância. 
O terceiro item acima implica justificar legalmente a convivência de duas figuras curriculares - uma obrigatória e outra opcional -, sendo que, nesta condição (opcional), o PRP caracteriza-se como estágio não obrigatório, ferindo o disposto no art. $2^{\circ}$ da Lei $11.788 / 2008$ - aliás, documento que sequer é mencionado nos editais de que nos ocupamos aqui:

Art. $2^{\circ} \mathrm{O}$ estágio poderá ser obrigatório ou nãoobrigatório, conforme determinação das diretrizes curriculares da etapa, modalidade e área de ensino e do projeto pedagógico do curso.

$\S 1^{\circ}$ Estágio obrigatório é aquele definido como tal no projeto do curso, cuja carga horária é requisito para aprovação e obtenção de diploma.

$\S 2^{\circ}$ Estágio não obrigatório é aquele desenvolvido como atividade opcional, acrescida à carga horária regular e obrigatória. (grifos nossos)

Até que ponto seria aplicável o previsto no $\$ 3^{\circ}$ desse mesmo artigo ("As atividades de extensão, de monitorias e de iniciação científica na educação superior, desenvolvidas pelo estudante, somente poderão ser equiparadas ao estágio em caso de previsão no projeto pedagógico do curso")? Isso ocorrendo, teríamos dois mecanismos distintos para cumprimento do mesmo componente obrigatório, mas com condições de operacionalização diferenciadas, em franco desrespeito à isonomia que deve pautar as ações da Administração Pública. Essa diferença de tratamento interfere nas relações com as escolas-campo, que obviamente vão se tornar mais disponíveis ao PRP que ao estágio curricular.

Note-se que essa última observação nos faz retornar ao item 2, posto que quaisquer mudanças nas condições oferecidas vão modificar as relações estabelecidas com as escolas-campo.

O lançamento de um programa que pretende extrapolar essa condição e converter-se em figura curricular tem de se fazer acompanhar de um horizonte de perspectivas, para que não reste como um satélite orbitando em torno do currículo, agindo sobre ele, mas a poucos beneficiando com sua luz.

Sem a definição desses aspectos, é temerário conceder equivalência entre a carga horária desenvolvida no PRP e a do estágio curricular obrigatório, até porque não há garantia da manutenção das condições que tornam atrativo o PRP - muito recentemente, vivenciamos a angústia de o PIBID vir a ser cancelado. Daí a necessidade de um verdadeiro diálogo entre as duas modalidades, visando um ajuste mútuo para se criarem condições de implementação efetiva dessa etapa do percurso formativo dos licenciandos. Diálogos, para assim se caracterizarem, devem ocorrer em concomitância temporal. 


\section{CONSIDERAÇÕES FINAIS}

É importante ficar claro que não se pretende aqui repudiar a figura do PRP, pelo contrário, em função do riquíssimo campo de investigação que ela abre para o enfrentamento das dificuldades operacionais do estágio. O aspecto que queremos ver realçado na discussão aqui empreendida é o de que o lançamento - desejável, frise-se - de propostas voltadas às atividades de estágio (ou o nome que lhe derem) não deve servir de pretexto para que o estágio obrigatório deixe de ser discutido como se resolvido estivesse.

O que se quer ver posto em pauta é o inadiável enfrentamento do estágio curricular obrigatório nas suas peculiaridades, e nestas considerações finais, aproveitamos para chamar a atenção para um aspecto que entendemos ser um caminho produtivo no sentido de compreender as dificuldades que tornam o estágio um tema espinhoso.

Parece-nos que a falta de enfrentamento das dificuldades do modelo atual de estágio passa por uma análise das especificidades operacionais - aspecto a que o PRP parece oferecer uma rica contribuição, desde que superadas as limitações quanto ao público beneficiado.

Se, do ponto de vista conceitual, o estágio obrigatório para a formação de professores atingiu um nível que identifica especificidades, do ponto de vista operacional, contudo, continua refém do modelo de estágio do bacharelado, que as suprime. Um breve olhar na constituição do estágio de formação de professores permite identificar uma apropriação irrefletida dos formatos de estágios dos bacharelados. Se estes se sentem absolutamente à vontade nessa roupagem, as licenciaturas sufocam.

Consideramos que é uma reflexão que precisa ser feita em âmbito geral, não cabendo no escopo e nos limites deste artigo.

Por ora, faz-se necessário reabrir a discussão sobre a equivalência entre Estágio Supervisionado e horas de atividades no PRP. 


\section{REFERÊNCIAS}

ANPED. A política de formação de professores no Brasil de 2018: uma análise dos Editais CAPES de Residência Pedagógica e PIBID e a reafirmação da resolução CNE/CP 02/2015. Rio de Janeiro, ANPED, 2018. Disponível em: http://www.anped.org.br/news/em-audiencia-no-cne-anped-e-entidades-de-pesquisa-repudiam-submissao-de-formacao-de-professores. Acesso em: $1^{\circ}$ maio 2020.

ANPED, ANFOPE et al. Nota das entidades em relação à Residência Pedagógica. Disponível em: https:// www.fe.unicamp.br/pf-fe/noticia/3946/manifesto_programa_residencia_pedagogica.pdf. Acesso em: 14 maio 2020.

ARAÚJO, O. H. A. "Nova" Política Nacional de Formação de Professores com residência pedagógica: para onde caminha o estágio supervisionado? Série Estudos, Campo Grande, MS, v. 24, n. 52, p. 253-273, set./ dez. 2019. Disponível em:https://www.serie-estudos.ucdb.br/serie-estudos/article/view/1270. Acesso em: 10 abr. 2020.

BAZZO, V. L.; SCHEIBE, L. De volta para o futuro... retrocessos na atual política de formação docente. Revista Retratos da Escola, Brasília, 13(27), 669-684, set./dez, 2019. Disponível em: http://retratosdaescola.emnuvens.com.br/rde/article/view/1038. Acesso em: 02 jun. 2020.

BRASIL. Edital CAPES 01/2020 que dispõe sobre a Residência Pedagógica. Disponível em: https://capes. gov.br/images/novo_portal/editais/editais/06012020-Edital-1-2020-Resid\%C3\%AAncia-Pedag\% C3\%B3gica. pdf. Acesso em: 05 mar. 2020.

BRASIL. Edital CAPES 06/2018 que dispõe sobre a Residência Pedagógica. Disponível em: https://www. capes.gov.br/images/stories/download/editais/01032018-Edital-6-2018-Residencia-pedagogica.pdf. Acesso em: 20 fev. 2020.

BRASIL. Lei n 13.005, de 25 de junho de 2014. Aprova o Plano Nacional de Educação - PNE e dá outras providências. Disponível em: http://pne.mec.gov.br/18-planos-subnacionais-de-educacao/543-plano-nacional-de-educacao-lei-n-13-005-2014. Acesso em: 18 mar. 2020.

BRASIL. Lei $\mathbf{n}^{\circ}$ 11788, de 25 de setembro de 2008. Dispõe sobre o estágio de estudantes. Disponível em: http://www.planalto.gov.br/ccivil_03/_ato2007-2010/2008/lei//11788.htm. Acesso em: 30 abr. 2020.

BRASIL. Ministério da Educação. Lei Nº 9.394/1996. Lei de Diretrizes e Bases de Educação (LDB). Estabelece as diretrizes e bases da Educação Nacional. Disponível em: http://www.planalto.gov.br/ccivil_03/leis//9394.htm. Acesso em: 02 fev. 2020.

BRASIL. Parecer CNE/CP 28/2001. Conselho Nacional de Educação/Conselho Pleno. Diário Oficial da União de 18/02/2002.

BRASIL. Portaria $\mathbf{n}^{\circ} \mathbf{2 5 9}$, de 17 dezembro de 2019. Dispõe sobre o regulamento do Programa de Residência Pedagógica e do Programa Institucional de Bolsa de Iniciação à Docência (PIBID). Disponível em: https:// www.capes.gov.br/images/novo_portal/documentos/regulamento/19122019_Portaria_259_Regulamento.pdf. Acesso em: 19 fev. 2020. 
BRASIL. Resolução CNE/CP 02, de $1^{\circ}$ de julho de 2015. Define as Diretrizes Curriculares Nacionais para a formação inicial em nível superior (cursos de licenciatura, cursos de formação pedagógica para graduados e cursos de segunda licenciatura) e para a formação continuada. Conselho Nacional de Educação/Conselho Pleno. Diário Oficial da União de 25/06/2015.

BRASIL. Resolução CNE/CP 02, de 20 de dezembro de 2019. Define as Diretrizes Curriculares Nacionais para a Formação Inicial de Professores para a Educação Básica e institui a Base Nacional Comum para a Formação Inicial de Professores da Educação Básica (BNC-Formação). Conselho Nacional de Educação/ Conselho Pleno. Diário Oficial da União de 20/12/2020.

CINTRA, P. C. S.; COSTA, R. L. Diretrizes Curriculares Nacionais paraformação de professores para Educação Básica de 2015 e 2019: Perspectivas prática e emancipadora. Research, Society and Development, v. 9, n. 9, 2020. Disponível em:https://www.serie-estudos.ucdb.br/serie-estudos/article/view/1270. Acesso em: 29 jul. 2020.

JARDILINO, José Rubens Lima. Políticas de formação de professores em conflito com o currículo: estágio supervisionado e PIBID. In: Revista Educação, Santa Maria, v. 39, n. 2, p. 353-366, maio/ago. 2014. Disponível em: http://www.repositorio.ufop.br/bitstream/123456789/4934/1/ARTIGO_Pol\%C3\%ADticasForma\%C3\%A 7\% C3\%A3oProfessores.pdf. Acesso em: 31 maio 2020.

PIMENTA, S. G.; LIMA, M. S. L. Estágio e docência. 5. ed. São Paulo: Cortez, 2010.

PIMENTA, S. G.; LIMA, M. S. L. Estágios Supervisionados e o Programa Institucional de Bolsa de Iniciação à Docência: duas faces da mesma moeda? Revista Brasileira de Educação, v. 24, 2019. Disponível em: https://www.scielo.br/scielo.php?script=sci_arttext\&pid=S1413-24782019000100200\&tlng=pt. Acesso em: 13 mar. 2020.

RODRIGUES, Micaías Andrade. Quatro diferentes visões sobre o estágio supervisionado. Rev. Bras. Educ., Rio de Janeiro, v. 18, n. 55, p. 1009-1034, Dec. 2013. Disponível em: http://www.scielo.br/scielo.php?script=sci_ arttext\&pid=S1413-24782013000400011\&lng=en\&nrm=iso. Acesso em: 02 jun. 2020.

SILVA, K. A. C. P.; CRUZ, S. P. A Residência Pedagógica na formação de professores: história, hegemonia e resistências. Momento: diálogos em educação, v. 27, n. 2, p. 227-247, mai./ago, 2018. Disponível em: https://periodicos.furg.br/momento/article/view/8062. Acesso em: 22 jun. 2020.

UFG. Fórum de Licenciaturas. Nota de Repúdio do Fórum de Licenciaturas ao Edital n 6/2018 CAPES, referente à Residência Pedagógica. Disponível em: https://forumlicenciatura.prograd.ufg.br/n/104913-residenciapedagogica. Acesso em: 04 nov. 2018.

UFPR. CEALI. Avaliação dirigida à comunidade universitária sobre o Edital Capes $\mathbf{n}^{\circ}$ 06/2018, que institui o Programa de Residência Pedagógica. Curitiba: CEALI, 2018.

VÁSQUEZ, A. Filosofia da práxis. Rio de Janeiro: Paz e Terra, 1968.

VELOSO, F. S.; PIVOVAR, A.; Residência Pedagógica nas IES: programa de aperfeiçoamento do estágio curricular obrigatório? Formação Docente - Revista Brasileira de Pesquisa sobre Formação de Professores. Belo Horizonte. Vol. 13, nº. 26 (p. 185-198) 30 abr. 2021. ISSN:2176-4360. DOI https://doi.org/10.31639/rbpfp.v13i26.416 